\title{
Study of the seismodynamics of spatially located underground pipelines with a nodal connection of non-orthogonal configuration
}

\author{
Ibrakhim Mirzaev ${ }^{1}$, Ruslan Kishanov ${ }^{2 *}$, Nodirakhon Mansurova ${ }^{3}$, Nematilla Nishonov $^{1}$, \\ Mars Berdibaev ${ }^{1}$ \\ ${ }^{1}$ Academy of Sciences of the Republic of Uzbekistan Institute of Mechanics and Seismic Stability of \\ Structures named after M.T. Urazbayev, Tashkent, Uzbekistan \\ ${ }^{2}$ Tashkent State Transport University, Tashkent, Uzbekistan \\ ${ }^{3}$ Namangan Engineering Construction Institute, Namangan, Uzbekistan
}

\begin{abstract}
The article deals with the seismodynamics of underground pipelines of various configurations under spatial seismic influences. The stress-strain state of spatially located underground pipelines of complex orthogonal configuration at different angles of seismic load incidence was determined. Several problems were solved by analyzing numerical results of the seismodynamics of underground pipelines of complex orthogonal and non-orthogonal configurations.
\end{abstract}

\section{Introduction}

The seismic motion of the Earth's crust contributes to the appearance of substantial horizontal and vertical strains in soil that can lead to accidents in underground pipelines [14].

In the past, the seismic design of buried structures has received less attention than the design of surface structures [3-7]. The methods for calculating non-orthogonally connected underground-extended structures with arbitrarily directed seismic effects were developed.

Scientific theoretical and experimental research on the strength of underground pipelines under seismic loads was conducted by such prominent scientists of the world as M.J. O'Rourke, L.R. Wang, N. Suzuki, A. Sakurai, T.D. O'Rourke, N.M. Newmark, El. Hmadi, T. Takahashi, T. Tanaka, K. Yoshizaki, X.L. Liu, I.C. Anderson, S.B. Johnston, V. Corrado, D.D. Barkan, T.R. Rashidov, V.A. Ilyichev, Ya.M. Eisenberg, A.G. Nazarov, A.B. Einbinder, Sh.G. Napetvaridze, A.S. Gekhman, A.A. Alexandrov, R.A. Gumerov, E.N. Figarov and many others who dealt with seismic resistance of structures working in the world's leading scientific centers, universities, and research institutes [5-20].

M.J. O'Rourke and X.L. Liu (1999) discussed the results of theoretical and practical research in the field of seismic resistance of underground pipelines in detail in their monograph. A deep analysis of the results of this monographic study allows us to trace the history of the formation and development of the seismodynamics in different countries of the world. There are some empirical results abroad related to the development of

\footnotetext{
*Corresponding author: kishanov_r@mail.ru
} 
recommendations for earthquake-resistant construction of underground pipelines located in special soil conditions. Many priorities in this field belong to the scientists of Uzbekistan.

\section{Methods}

Let us consider a non-orthogonally connected piping system. The theoretical and computational experimental studies conducted are aimed at solving the problem of assessing the stress-strain state of non-orthogonal (Fig. 1) pipeline systems under seismic loads directed arbitrarily relative to the main axes of the structure [17].

Figure 1 shows a system of pipelines and wells of a non-orthogonal configuration, modeled as a rigid body with rigid joints interacting with soil. The wells have a cylindrical shape, according to which the mass moments of inertia and the coefficients of interaction with soil are calculated. Let us study the effect of the well mass on the stress state of an underground pipeline under the influence of a spatial seismic load.

Consider an underground pipeline of a length of $172 \mathrm{~m}$, to which 4 nodes are connected at sections of $41 \mathrm{~m}, 85 \mathrm{~m}, 88 \mathrm{~m}$ and $132 \mathrm{~m}$ (see Figure 1).

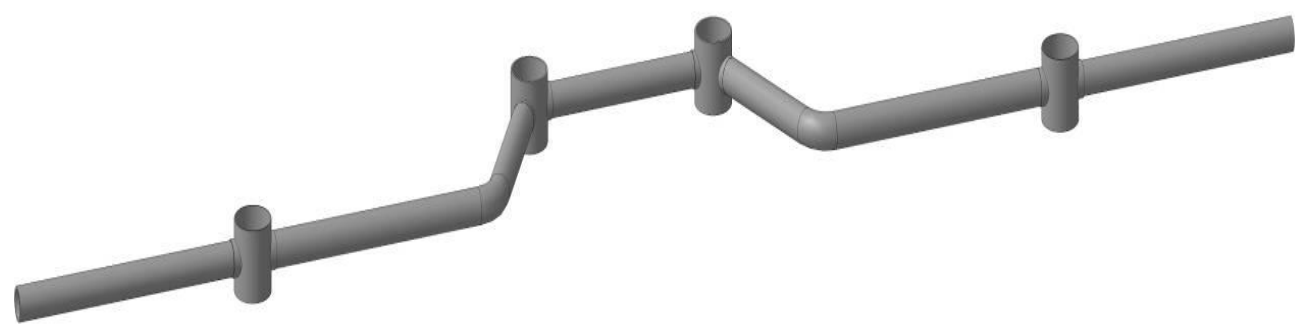

Fig. 1. Section of a complex system of underground pipelines of non-orthogonal configuration

\section{Results and Discussion}

As an example, let us consider the following problem. Mechanical and geometrical parameters of the underground pipeline and soil are selected in the following form: $E=2 \cdot 10^{5} \mathrm{MPa} ; \rho=7.8 \cdot 10^{3} \mathrm{~kg} / \mathrm{m}^{3} ; D_{H}=0.5 \mathrm{~m} ; D_{B}=0.49 \mathrm{~m} ; \mu_{\text {soil }}=0.2 ; \mu_{\text {pipe }}=0.3 ; l=172 \mathrm{~m}$; in the straight section $k_{x}=1.5 \cdot 10^{4} \mathrm{kN} / \mathrm{m}^{3} ; \quad k_{y, z}=3.9 \cdot 10^{4} \mathrm{kN} / \mathrm{m}^{3} ; \quad$ in the complex section $k_{x}=0.5 \cdot 10^{4} \mathrm{kN} / \mathrm{m}^{3} ; k_{y, z}=1.3 \cdot 10^{4} \mathrm{kN} / \mathrm{m}^{3} ; u_{0}=a_{0} \cdot \sin \omega\left(t-x \cdot \cos \alpha / C_{p}\right) \cdot H\left(t-x \cdot \cos \alpha / C_{p}\right) ; a_{0}=0.008 \mathrm{~m}$; $C_{p}=500 \mathrm{~m} / \mathrm{s} ; u_{0 x}=u_{0} \cdot \cos \alpha ; u_{0 y}=u_{0} \cdot \sin \alpha \cdot \cos \beta ; u_{0 z}=u_{0} \cdot \sin \alpha \cdot \sin \beta$.

The parameters of the well are $E=2.5 \cdot 10^{4} \mathrm{MPa} ; \rho=2.5 \cdot 10^{3} \mathrm{~kg} / \mathrm{m}^{3} ; D_{H}^{u z}=1 \mathrm{~m} ; D_{B}^{u z}=0.9 \mathrm{~m}$; $H_{u z}=1 \mathrm{~m} ; m_{1}=\pi \cdot H_{u z} / 4 \cdot\left(D_{H}^{u z^{2}}-D_{B}^{u z^{2}}\right) \cdot \rho ; m_{2}=\pi \cdot R_{H}^{u z^{2}} \cdot h_{u z} \cdot \rho ; m_{u z}=V_{1} \cdot \rho$; $I_{x}^{u z}=I_{y}^{u z}=m_{1} / 12 \cdot H_{u z}{ }^{2}+1 / 2 \cdot m_{2} \cdot R_{H}^{u z^{2}} \mathrm{~m}^{2} ; I_{z}^{u z}=m_{1} / 2 \cdot\left(R_{H}^{u z^{2}}+R_{B}^{u z^{2}}\right)+m_{2} \cdot R_{H}^{u z^{2}} \mathrm{~m}^{2} ;$ $V_{l}=\pi \cdot H_{u z} / 4 \cdot\left(D_{H}^{u z^{2}}-D_{B}^{u z^{2}}\right)+2 \cdot \pi \cdot R_{H}^{u z^{2}} \cdot h_{u z} ; k_{x}^{u z}=0.5 \cdot 10^{4} \mathrm{kN} / \mathrm{m}^{3} ; k_{y, z}{ }^{u z}=1.3 \cdot 10^{4} \mathrm{kN} / \mathrm{m}^{3}$, to account for the mass of a given rigid node.

Let us analyze the results obtained. The results of solving the problem are presented in the form of graphs and tables. Let us consider the influence of arbitrary seismic actions on a complex non-orthogonal underground pipeline at different angles of incidence of a seismic wave $\alpha=30^{\circ}, \beta=30^{\circ}$.

Table 1 shows the values of the longitudinal displacement of a complex non-orthogonal underground pipeline (see Figure 1) at an arbitrary angle of attack of the impact at given 
time points. The main large longitudinal displacements are observed in non-orthogonal sections $(x=88 \mathrm{~m}, x=92 \mathrm{~m})$.

Table 1. Values of longitudinal displacement of the pipeline at angles of incidence of a seismic wave $\alpha=30^{\circ}, \beta=30^{\circ}$

\begin{tabular}{|c|c|c|c|c|c|c|}
\hline$t, \mathrm{~s}$ & $\begin{array}{c}u, \mathrm{~m}, \\
x=41 \mathrm{~m}\end{array}$ & $\begin{array}{c}u, \mathrm{~m}, \\
x=81 \mathrm{~m}\end{array}$ & $\begin{array}{c}u, \mathrm{~m}, \\
x=85 \mathrm{~m}\end{array}$ & $\begin{array}{c}u, \mathrm{~m}, \\
x=88 \mathrm{~m}\end{array}$ & $\begin{array}{c}u, \mathrm{~m}, \\
x=92 \mathrm{~m}\end{array}$ & $\begin{array}{c}u, \mathrm{~m}, \\
x=132 \mathrm{~m}\end{array}$ \\
\hline 0.1 & 0.004808 & 0.001366 & 0.000939 & 0.000869 & 0.000357 & $4.25 \mathrm{E}-05$ \\
\hline 0.2 & 0.000675 & 0.005212 & 0.006142 & 0.006257 & 0.007033 & 0.004381 \\
\hline 0.3 & -0.00595 & -0.00572 & -0.00523 & -0.00514 & -0.0045 & 0.001272 \\
\hline 0.4 & 0.00528 & 0.000574 & -0.00093 & -0.00114 & -0.00266 & -0.00625 \\
\hline 0.5 & 0.000668 & 0.00515 & 0.006157 & 0.006283 & 0.007162 & 0.004975 \\
\hline 0.6 & -0.00595 & -0.00572 & -0.00523 & -0.00514 & -0.0045 & 0.001271 \\
\hline 0.7 & 0.00528 & 0.000573 & -0.00093 & -0.00114 & -0.00266 & -0.00625 \\
\hline 0.8 & 0.000668 & 0.00515 & 0.006157 & 0.006283 & 0.007162 & 0.004975 \\
\hline 0.9 & -0.00595 & -0.00572 & -0.00523 & -0.00514 & -0.0045 & 0.001271 \\
\hline 1 & 0.005198 & 0.000441 & -0.00107 & -0.00128 & -0.0028 & -0.00629 \\
\hline
\end{tabular}

Table 2 shows the values of the transverse displacement of a complex non-orthogonal underground pipeline (see Figure 1) at an arbitrary angle of attack of the impact at given time points.

Tables 1 and 2 show that large longitudinal and transverse displacements are observed in the nodal sections ( $x=41 \mathrm{~m}, x=85 \mathrm{~m}, x=88 \mathrm{~m}, x=132 \mathrm{~m}$, see Table 2).

Tables 1 and 2 show that the values of the transverse and vertical displacements are less than the longitudinal displacement. It depends on the angles of incidence of seismic action $\alpha$ and $\beta$.

Table 2. Values of transverse displacement of the pipeline at angles of incidence of the seismic wave $\alpha=30^{\circ}, \beta=30^{\circ}$

\begin{tabular}{|c|c|c|c|c|c|c|}
\hline$t, \mathrm{~s}$ & $\begin{array}{c}\mathrm{v}, \mathrm{m}, \\
x=41 \mathrm{~m}\end{array}$ & $\begin{array}{c}\mathrm{v}, \mathrm{m}, \\
x=81 \mathrm{~m}\end{array}$ & $\begin{array}{c}\mathrm{v}, \mathrm{m}, \\
x=85 \mathrm{~m}\end{array}$ & $\begin{array}{c}\mathrm{v}, \mathrm{m}, \\
x=88 \mathrm{~m}\end{array}$ & $\begin{array}{c}\mathrm{v}, \mathrm{m}, \\
x=92 \mathrm{~m}\end{array}$ & $\begin{array}{c}\mathrm{v}, \mathrm{m}, \\
x=132 \mathrm{~m}\end{array}$ \\
\hline 0.1 & 0.003473 & 0.000998 & 0.001154 & 0.000894 & 0.000649 & $-1.8 \mathrm{E}-07$ \\
\hline 0.2 & -0.00171 & $1.34 \mathrm{E}-05$ & -0.00039 & -0.00022 & 0.000141 & 0.001904 \\
\hline 0.3 & -0.00176 & -0.00297 & -0.00317 & -0.00326 & -0.003 & -0.00346 \\
\hline 0.4 & 0.003469 & 0.00295 & 0.003596 & 0.003519 & 0.002849 & 0.001544 \\
\hline 0.5 & -0.00171 & $1.55 \mathrm{E}-05$ & -0.00042 & -0.00026 & 0.00015 & 0.001919 \\
\hline 0.6 & -0.00176 & -0.00297 & -0.00317 & -0.00326 & -0.003 & -0.00346 \\
\hline 0.7 & 0.003469 & 0.00295 & 0.003596 & 0.003519 & 0.00285 & 0.001544 \\
\hline 0.8 & -0.00171 & $1.55 \mathrm{E}-05$ & -0.00042 & -0.00026 & 0.00015 & 0.001919 \\
\hline 0.9 & -0.00176 & -0.00297 & -0.00317 & -0.00326 & -0.003 & -0.00346 \\
\hline 1 & 0.003468 & 0.002913 & 0.003562 & 0.003482 & 0.002811 & 0.001478 \\
\hline
\end{tabular}

Table 3 shows the values of vertical displacement of a complex non-orthogonal underground pipeline (see Fig. 1) at an arbitrary angle of attack of the impact at given time points. The seismic motion of the Earth's crust contributes to the appearance of substantial horizontal and vertical deformations of soil and can lead to accidents in underground pipelines.

The non-uniform motion of soil under strong ground motion is described by several parameters, including peak acceleration, peak velocity, peak displacement, response spectra, duration, etc. 
Table 3. Values of vertical displacement of the pipeline at angles of incidence of a seismic wave

\begin{tabular}{|c|c|c|c|c|c|c|}
\hline$t, \mathrm{~s}$ & $\begin{array}{c}w, \mathrm{~m}, \\
x=41 \mathrm{~m}\end{array}$ & $\begin{array}{c}w, \mathrm{~m}, \\
x=81 \mathrm{~m}\end{array}$ & $\begin{array}{c}w, \mathrm{~m}, \\
x=85 \mathrm{~m}\end{array}$ & $\begin{array}{c}w, \mathrm{~m}, \\
x=88 \mathrm{~m}\end{array}$ & $\begin{array}{c}w, \mathrm{~m}, \\
x=92 \mathrm{~m}\end{array}$ & $\begin{array}{c}w, \mathrm{~m}, \\
x=132 \mathrm{~m}\end{array}$ \\
\hline 0.1 & 0.00196 & 0.000686 & 0.000524 & 0.000397 & 0.000312 & $-1.6 \mathrm{E}-07$ \\
\hline 0.2 & -0.00135 & -0.00085 & -0.00083 & -0.00081 & -0.00079 & -0.00021 \\
\hline 0.3 & -0.00061 & -0.00115 & -0.00117 & -0.00119 & -0.0012 & -0.00162 \\
\hline 0.4 & 0.001957 & 0.002 & 0.001999 & 0.001993 & 0.001988 & 0.00183 \\
\hline 0.5 & -0.00135 & -0.00085 & -0.00083 & -0.00081 & -0.00079 & -0.00021 \\
\hline 0.6 & -0.00061 & -0.00115 & -0.00117 & -0.00118 & -0.0012 & -0.00162 \\
\hline 0.7 & 0.001957 & 0.002 & 0.001999 & 0.001993 & 0.001988 & 0.001829 \\
\hline 0.8 & -0.00135 & -0.00085 & -0.00083 & -0.00081 & -0.00079 & -0.00021 \\
\hline 0.9 & -0.00061 & -0.00115 & -0.00117 & -0.00118 & -0.0012 & -0.00162 \\
\hline 1 & 0.001965 & 0.001996 & 0.001994 & 0.001988 & 0.001982 & 0.001812 \\
\hline
\end{tabular}

A complex stress-strain state arises in the sections of an underground pipeline under spatial seismic loads (including real records of earthquakes).

Table 4 shows the values of the compressive (tensile) stresses of a complex nonorthogonal underground pipeline (see Fig. 1) at an arbitrary angle of attack of the impact at specified time points.

Table 4. Values of compressive (tensile) stress of the pipeline at angles of incidence of the seismic wave $\alpha=30^{\circ}, \beta=30^{\circ}$

\begin{tabular}{|c|c|c|c|c|c|c|}
\hline$t, \mathrm{~s}$ & $\begin{array}{c}\sigma, \mathrm{MPa}, \\
x=41 \mathrm{~m}\end{array}$ & $\begin{array}{c}\sigma, \mathrm{MPa}, \\
x=81 \mathrm{~m}\end{array}$ & $\begin{array}{c}\sigma, \mathrm{MPa}, \\
x=85 \mathrm{~m}\end{array}$ & $\begin{array}{c}\sigma, \mathrm{MPa}, \\
x=88 \mathrm{~m}\end{array}$ & $\begin{array}{c}\sigma, \mathrm{MPa}, \\
x=92 \mathrm{~m}\end{array}$ & $\begin{array}{c}\sigma, \mathrm{MPa}, \\
x=132 \mathrm{~m}\end{array}$ \\
\hline 0.1 & -19.303 & -4.31592 & -4.75566 & -1.10934 & -3.5966 & -0.44546 \\
\hline 0.2 & 32.24989 & 4.229893 & 7.900137 & 2.393436 & 4.596716 & -24.5775 \\
\hline 0.3 & -12.8586 & 2.892921 & 5.434314 & 4.623389 & 9.177464 & 33.08401 \\
\hline 0.4 & -19.2942 & -7.2995 & -14.0758 & -7.37871 & -14.6794 & -9.69952 \\
\hline 0.5 & 32.13648 & 4.422541 & 8.627922 & 2.78508 & 5.538153 & -23.4535 \\
\hline 0.6 & -12.8419 & 2.88204 & 5.447056 & 4.602501 & 9.150778 & 33.15531 \\
\hline 0.7 & -19.2941 & -7.30286 & -14.0742 & -7.3845 & -14.6857 & -9.70036 \\
\hline 0.8 & 32.13619 & 4.421375 & 8.627585 & 2.783056 & 5.535994 & -23.4545 \\
\hline 0.9 & -12.842 & 2.881663 & 5.446785 & 4.601807 & 9.150055 & 33.155 \\
\hline 1 & -19.8337 & -7.32 & -14.1097 & -7.36113 & -14.639 & -9.01385 \\
\hline
\end{tabular}

In straight sections (see Table 4; sections $x=41 \mathrm{~m}(t=0.2 \mathrm{~s}, t=0.5 \mathrm{~s}, t=0.8 \mathrm{~s})$ and $x=132 \mathrm{~m}$ $(t=0.3 \mathrm{~s}, t=0.6 \mathrm{~s}, t=0.9 \mathrm{c}))$ near the nodes, the compressive (tensile) stresses are greater than in other sections of the underground pipeline.

Table 5 shows the values of the total stresses $\left(\sigma_{y}^{+}\right)$of a complex non-orthogonal underground pipeline (see Fig. 1) at an arbitrary angle of attack of the impact at given time points.

If the structure uses rigid joints on the contact surface, then additional bending and shear stresses develop near the contact. 
Table 5. Values of total stresses $\left(\sigma_{\mathrm{y}}{ }^{+}\right)$of the pipeline at angles of incidence of a seismic wave $\alpha=30^{\circ}$, $\beta=30^{\circ}$

\begin{tabular}{|c|c|c|c|c|c|c|}
\hline$t, \mathrm{~s}$ & $\begin{array}{c}\sigma_{\mathrm{y}}^{+}, \\
\mathrm{MPa}, \\
x=41 \mathrm{~m}\end{array}$ & $\begin{array}{c}\sigma_{\mathrm{y}}^{+}, \\
\mathrm{MPa}, \\
x=81 \mathrm{~m}\end{array}$ & $\begin{array}{c}\sigma_{\mathrm{y}}^{+}, \mathrm{MPa}, \\
x=85 \mathrm{~m}\end{array}$ & $\begin{array}{c}\sigma_{\mathrm{y}}^{+}, \\
\mathrm{MPa}, \\
x=88 \mathrm{~m}\end{array}$ & $\begin{array}{c}\sigma_{\mathrm{y}}^{+}, \\
\mathrm{MPa}, \\
x=92 \mathrm{~m}\end{array}$ & $\begin{array}{c}\sigma_{\mathrm{y}}^{+}, \\
\mathrm{MPa}, \\
x=132 \mathrm{~m}\end{array}$ \\
\hline 0.1 & -19.1178 & $-5,08267$ & -10.3607 & -0.13438 & -2.56355 & -0.44485 \\
\hline 0.2 & 32.28492 & 3.483252 & 9.557359 & 3.332706 & 4.247234 & -24.3765 \\
\hline 0.3 & -12.9814 & 2.213378 & 5.613973 & 6.062049 & 9.41226 & 32.98686 \\
\hline 0.4 & -19.1922 & -5.81939 & -16.0399 & -9.9335 & -14.6186 & -9.65931 \\
\hline 0.5 & 32.15982 & 3.621034 & 10.4013 & 3.891726 & 5.230383 & -23.3541 \\
\hline 0.6 & -12.9669 & 2.202807 & 5.634461 & 6.047844 & 9.394959 & 33.02884 \\
\hline 0.7 & -19.1925 & -5.82242 & -16.036 & -9.93724 & -14.6227 & -9.66912 \\
\hline 0.8 & 32.15952 & 3.620051 & 10.40165 & 3.890236 & 5.228723 & -23.3579 \\
\hline 0.9 & -12.967 & 2.202503 & 5.63441 & 6.0473 & 9.394348 & 33.02762 \\
\hline 1 & -19.7339 & -5.83837 & -16.0901 & -9.90917 & -14.5694 & -8.98562 \\
\hline
\end{tabular}

Table 6 shows the values of the total stresses $\left(\sigma_{y}^{-}\right)$of a complex non-orthogonal underground pipeline (see Fig. 1) at an arbitrary angle of attack of the impact at given time points.

Table 6. Values of total stresses $\left(\sigma_{\mathrm{y}}^{-}\right)$of the pipeline at angles of incidence of a seismic wave $\alpha=30^{\circ}$, $\beta=30$

\begin{tabular}{|c|c|c|c|c|c|c|}
\hline$t, \mathrm{~s}$ & $\begin{array}{c}\sigma_{\mathrm{y}}{ }^{\circ}, \mathrm{MPa}, \\
x=41 \mathrm{~m}\end{array}$ & $\begin{array}{c}\sigma_{\mathrm{y}}{ }^{-}, \mathrm{MPa}, \\
x=81 \mathrm{~m}\end{array}$ & $\begin{array}{c}\sigma_{\mathrm{y}}{ }^{-}, \mathrm{MPa}, \\
x=85 \mathrm{~m}\end{array}$ & $\begin{array}{c}\sigma_{\mathrm{y}}{ }^{-}, \mathrm{MPa}, \\
x=88 \mathrm{~m}\end{array}$ & $\begin{array}{c}\sigma_{\mathrm{y}}{ }^{-}, \mathrm{MPa}, \\
x=92 \mathrm{~m}\end{array}$ & $\begin{array}{c}\sigma_{\mathrm{y}}{ }^{-}, \mathrm{MPa}, \\
x=132 \mathrm{~m}\end{array}$ \\
\hline 0.1 & -19.4881 & -3.54917 & 0.849339 & -2.08429 & -4.62965 & -0.44607 \\
\hline 0.2 & 32.21486 & 4.976534 & 6.242915 & 1.454166 & 4.946198 & -24.7785 \\
\hline 0.3 & -12.7359 & 3.572464 & 5.254654 & 3.184729 & 8.942668 & 33.18117 \\
\hline 0.4 & -19.3961 & -8.77961 & -12.1117 & -4.82392 & -14.7402 & -9.73973 \\
\hline 0.5 & 32.11315 & 5.224049 & 6.854542 & 1.678435 & 5.845924 & -23.5529 \\
\hline 0.6 & -12.7169 & 3.561274 & 5.259651 & 3.157159 & 8.906598 & 33.28178 \\
\hline 0.7 & -19.3957 & -8.78331 & -12.1124 & -4.83177 & -14.7486 & -9.7316 \\
\hline 0.8 & 32.11285 & 5.2227 & 6.853522 & 1.675875 & 5.843265 & -23.5511 \\
\hline 0.9 & -12.717 & 3.560824 & 5.25916 & 3.156314 & 8.905763 & 33.28238 \\
\hline 1 & -19.9336 & -8.80162 & -12.1292 & -4.81309 & -14.7086 & -9.04207 \\
\hline
\end{tabular}

Table 7 shows the values of total stresses $\left(\sigma_{\mathrm{z}}^{+}\right)$of a complex non-orthogonal underground pipeline (see Figure 1) at an arbitrary angle of attack of the impact at given time points.

Table 7. Values of total stress $\left(\sigma_{z}^{+}\right)$of the pipeline at angles of incidence of a seismic wave $\alpha=30^{\circ}$, $\beta=30^{\circ}$

\begin{tabular}{|c|c|c|c|c|c|c|}
\hline$t, \mathrm{~s}$ & $\begin{array}{c}\sigma_{\mathrm{z}}^{+}, \\
\mathrm{MPa}, \\
x=41 \mathrm{~m}\end{array}$ & $\begin{array}{c}\sigma_{\mathrm{z}}{ }^{+}, \\
\mathrm{MPa}, \\
x=81 \mathrm{~m}\end{array}$ & $\begin{array}{c}\sigma_{\mathrm{z}}{ }^{+}, \\
\mathrm{MPa}, \\
x=85 \mathrm{~m}\end{array}$ & $\begin{array}{c}\sigma_{\mathrm{z}}{ }^{+}, \\
\mathrm{MPa}, \\
x=88 \mathrm{~m}\end{array}$ & $\begin{array}{c}\sigma_{\mathrm{z}}{ }^{+}, \\
\mathrm{MPa}, \\
x=92 \mathrm{~m}\end{array}$ & $\begin{array}{c}\sigma_{\mathrm{z}}{ }^{+}, \\
\mathrm{MPa}, \\
x=132 \mathrm{~m}\end{array}$ \\
\hline 0.1 & -19.05 & -29.4019 & 10.50646 & 14.16663 & -8.31782 & -0.44515 \\
\hline 0.2 & 32.34083 & 28.25908 & -20.9636 & -22.6152 & 14.29195 & -24.1502 \\
\hline 0.3 & -13.0951 & 17.47751 & -11.9418 & -15.6854 & 32.63343 & 32.99797 \\
\hline 0.4 & -19.1349 & -47.445 & 34.93998 & 41.15538 & -50.2169 & -9.77176 \\
\hline 0.5 & 32.21565 & 29.93305 & -22.8873 & -25.3473 & 17.60114 & -23.2067 \\
\hline 0.6 & -13.0805 & 17.50062 & -12.0268 & -15.7788 & 32.61183 & 33.00823 \\
\hline 0.7 & -19.1349 & -47.4367 & 34.91994 & 41.13246 & -50.214 & -9.79129 \\
\hline 0.8 & 32.21545 & 29.93504 & -22.8917 & -25.3521 & 17.60182 & -23.2137 \\
\hline 0.9 & -13.0805 & 17.50127 & -12.0279 & -15.7799 & 32.61205 & 33.00602 \\
\hline 1 & -19.6784 & -47.5764 & 35.04335 & 41.23889 & -50.0214 & -9.11008 \\
\hline
\end{tabular}


Here, the nodes in complex sections of the underground pipeline play an important role since the total stresses increase near the nodes (see Tables $7-8$, sections $x=81 \mathrm{~m}, x=85 \mathrm{~m}$, $x=88 \mathrm{~m}, x=92 \mathrm{~m})$. This is due to bending deformations.

Table 8 shows the values of total stress $\left(\sigma_{\mathrm{z}}^{-}\right)$of a complex non-orthogonal underground pipeline (Fig. 1) at an arbitrary angle of attack of the impact at given time points.

In non-orthogonal complex sections of an underground pipeline (Tables $7-8$; sections $x=81 \mathrm{~m}, x=85 \mathrm{~m}, x=88 \mathrm{~m}, x=92 \mathrm{~m}, x=132 \mathrm{~m})$, the total stresses $\left(\sigma_{z}^{+}, \sigma_{z}{ }^{-}\right)$increase near the nodes.

Table 8. Values of total stress $\left(\sigma_{z}^{-}\right)$of the pipeline at angles of incidence of a seismic wave $\alpha=30^{\circ}$, $\beta=30^{\circ}$

\begin{tabular}{|c|c|c|c|c|c|c|}
\hline$t, \mathrm{~s}$ & $\begin{array}{c}\sigma_{\mathrm{z}}^{-}, \mathrm{MPa}, \\
x=41 \mathrm{~m}\end{array}$ & $\begin{array}{c}\sigma_{\mathrm{z}}^{-}, \mathrm{MPa}, \\
x=81 \mathrm{~m}\end{array}$ & $\begin{array}{c}\sigma_{\mathrm{z}}^{-}, \mathrm{MPa}, \\
x=85 \mathrm{~m}\end{array}$ & $\begin{array}{c}\sigma_{\mathrm{z}}^{-}, \mathrm{MPa}, \\
x=88 \mathrm{~m}\end{array}$ & $\begin{array}{c}\sigma_{\mathrm{z}}{ }^{-}, \mathrm{MPa}, \\
x=92 \mathrm{~m}\end{array}$ & $\begin{array}{c}\sigma_{\mathrm{z}}^{-}, \mathrm{MPa}, \\
x=132 \mathrm{~m}\end{array}$ \\
\hline 0.1 & -19.556 & 20.77008 & -20.0178 & -16.3853 & 1.124619 & -0.44576 \\
\hline 0.2 & 32.15896 & -19.7993 & 36.76391 & 27.40205 & -5.09851 & -25.0048 \\
\hline 0.3 & -12.6222 & -11.6917 & 22.81047 & 24.93215 & -14.2785 & 33.17006 \\
\hline 0.4 & -19.4534 & 32.84595 & -63.0916 & -55.9128 & 20.85807 & -9.62728 \\
\hline 0.5 & 32.05732 & -21.088 & 40.14316 & 30.91744 & -6.52484 & -23.7002 \\
\hline 0.6 & -12.6034 & -11.7365 & 22.92091 & 24.9838 & -14.3103 & 33.30239 \\
\hline 0.7 & -19.4532 & 32.83097 & -63.0683 & -55.9015 & 20.84264 & -9.60944 \\
\hline 0.8 & 32.05692 & -21.0923 & 40.14683 & 30.91824 & -6.52984 & -23.6954 \\
\hline 0.9 & -12.6036 & -11.7379 & 22.92144 & 24.98355 & -14.3119 & 33.30398 \\
\hline 1 & -19.989 & 32.9364 & -63.2627 & -55.9611 & 20.74341 & -8.91761 \\
\hline
\end{tabular}

As seen from the results of Tables $1-8$, the stress-strain state of a complex non-orthogonal underground pipeline depends on the angles of incidence of the seismic wave $\alpha$ and $\beta$, which is to be expected.

Let us consider a comparative assessment of the results obtained for underground nonorthogonal (see Fig. 1) and orthogonal pipelines (Figure 2) under spatial seismic influences. All initial data are taken as indicated earlier.

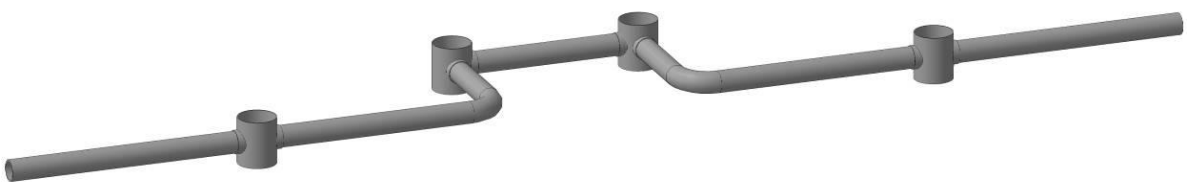

Fig. 2. Section of a complex system of underground pipelines of orthogonal configuration

Figure 3 shows the values of compressive (tensile) (a, b) and total (c, d) stresses along the axis of the underground pipeline at a fixed time point.
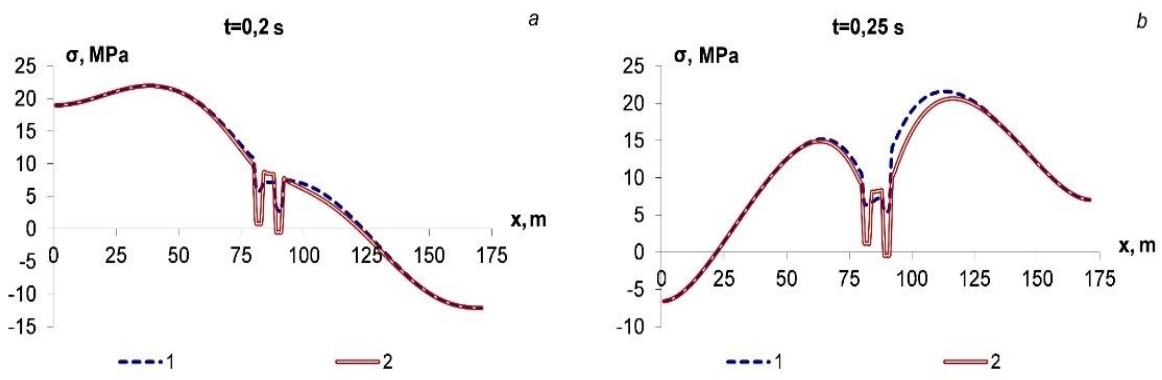

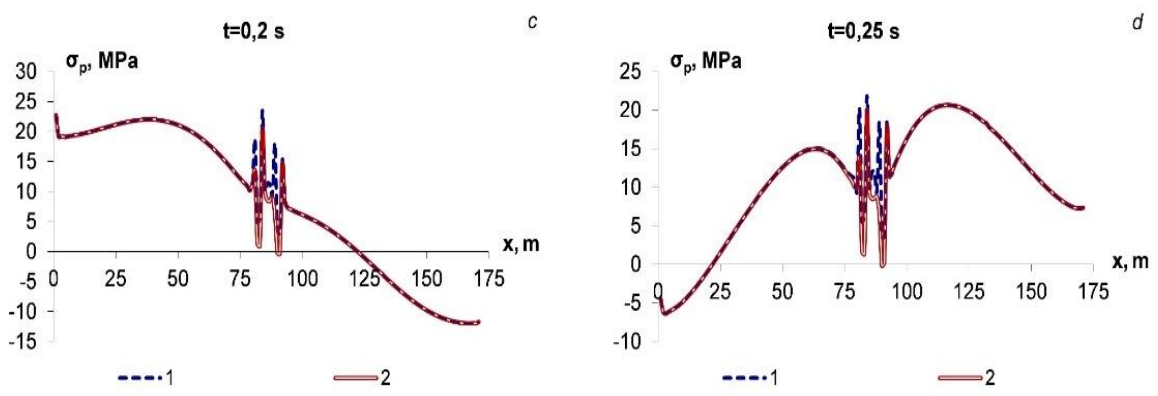

Fig. 3. Changes in the value of compressive (tensile) ( $a, b)$ and total (c, d) stresses along the axis of the underground pipeline at a fixed time point: 1-non-orthogonal configuration; 2-orthogonal configuration

It was determined that the total stress values in complex sections of underground pipelines of non-orthogonal configurations are greater than the total stresses in the pipelines of orthogonal configurations.

\section{Conclusions}

New problems related to the study of the stress-strain state of underground pipelines of various configurations under the influence of seismic loads propagating in an arbitrary direction were solved. The behavior of orthogonally and non-orthogonally connected pipelines at nodes with a well was investigated.

The results of the study of dynamic processes in pipeline systems using the developed software product were obtained; they could be recommended for specific calculations and design of underground life support systems in seismic zones.

A number of numerical results were obtained depending on the angle of incidence of the seismic wave. Hence, we can conclude that the presence of expansion joints, in general, leads to a decrease in axial stresses near these expansion joints to a distance of $20-30 \mathrm{~m}$.

The presented results provide a comprehensive analysis of the strength of underground pipelines under seismic impacts and implement a systematic approach to determine the consequences of an earthquake on the stress-strain rate of a pipeline and to plan engineering measures to ensure the safe and reliable operation of an underground pipeline in seismic areas.

\section{References}

1. Rashidov T.R., Yuldashev T, and Bekmirzaev D.A., Seismodynamics of Underground Pipelines with Arbitrary Direction of Seismic Loading, Soil Mech. Found. Eng. 55 pp. 243-248

2. Rashidov T.R., and Bekmirzaev D.A., Seismodynamics of Pipelines Interacting with the Soil Soil Mech. Found. Eng. 52 pp. 149-54 (2015)

3. Fard S.S., Nekooei M, Oskouei A.V., and Aziminejad A., Experimental and numerical modeling of horizontally-bent buried pipelines crossing fault slip Lat. Am. J. Solids Struct. 16 (2019)

4. Bekmirzaev D.A., Mirzaev I., Earthquake Resistance Assessment of Buried Pipelines of Complex Configuration Based on Records of Real Earthquakes Soil Mech. Found. Eng. pp.491-496 (2021)

5. Khachiyan E.E., 2015 On the possibility of predicting seismogram and accelerogram 
of strong motions of the soil for an earthquake model considered as an instantaneous rupture of the Earth's surface Seism. Instruments 51 pp. 129-40 (2015)

6. Bekmirzaev D.A., and Mirzaev I., Dynamic processes in underground pipelines of complex orthogonal configuration at different incidence angles of seismic effect Int. J. Sci. Technol. Res. 9 2449-53 (2020)

7. Stewart H, O'Rourke T, Ha D, Abdoun T, O'Rourke M and Van Laak P, Splitcontainers for centrifuge modeling of permanent ground deformation effects on buried pipeline systems Physical Modelling in Geotechnics (Taylor \& Francis) (2006)

8. Valeev A.R., Yalalov D.V., 2017 Analysis of methods of seismic protection of main pipelines Transport and storage of oil products and hydrocarbons 3 pp. 38-42 (2017)

9. Bekmirzaev D.A., Mirzaev I., Mansurova N.Sh., Kosimov E.A., and Juraev D, Numerical methods in the study of seismic dynamics of underground pipelines IOP Conf. Ser. Mater. Sci. Eng. 869 pp.052035 (2020)

10. O'Rourke M.J., and Liu J., Seismic loading and behavior of buried pipelines Am. Soc. Mech. Eng. Press. Vessel. Pip. Div. PVP (1998)

11. O'Rourke M., and Vargas-Londono T., Analytical Model for Segmented Pipe Response to Tensile Ground Strain Earthq. Spectra 32 pp. 2533-48 (2016)

12. Takada S., Hassani N., and Fukuda K., Damage Directivity in Buried Pipelines of Kobe City During the 1995 Earthquake J. Earthq. Eng. 0600050 (2002)

13. Saberi M, Behnamfar F., and Vafaeian M., A Continuum Shell-beam Finite Element Modeling of Buried Pipes with 90-degree Elbow Subjected to Earthquake Excitations Int. J. Eng. 28 (2015)

14. Bekmirzaev D.A., Kishanov R.U., and Mansurova N.Sh., Mathematical Simulation and Solution of the Problem of Seismo-Dynamics of Underground Pipelines Int. J. Emerg. Tr. Eng. Res. 8 5028-33 (2020)

15. Bekmirzaev D.A., Mansurova N.Sh., Nishonov N.A., Kosimov E.A., and Numonov A, Underground pipelines dynamics problem solution under longitudinal seismic loading IOP Conf. Ser. Mater. Sci. Eng. 883012045 (2020)

16. Nishonov N.A, Bekmirzaev D.A., An E.V., Urazmukhamedova Z and Turajonov K., Behaviour and Calculation of Polymer Pipelines Under Real Earthquake Records IOP Conf. Ser. Mater. Sci. Eng. 869052076 (2020)

17. Kosimov E.A., Mirzaev I, Bekmirzaev D.A., Comparison of the impacts of harmonic and seismic waves on an underground pipeline during the Gazli earthquake IOP Conf. Ser. Mater. Sci. Eng. 1030012082 (2021)

18. Zhuang H, Hu Z, Wang X, and Chen G., Seismic responses of a large underground structure in liquefied soils by FEM numerical modelling Bull. Earthq. Eng. 13 364568 (2015)

19. Saberi M, Arabzadeh H, Keshavarz A., Numerical Analysis of Buried Pipelines with Right Angle Elbow under Wave Propagation J. Procedia Engineering 14 3260-67 (2011)

20. O'Rourke T.D., Jung J.K., and Argyrou C., Underground pipeline response to earthquake-induced ground deformation Soil Dyn. Earthq. Eng. 91 272-83 (2016) 